\title{
Current and emerging treatments and surgical interventions for Morquio A syndrome: a review
}

This article was published in the following Dove Press journal:

Research and Reports in Endocrine Disorders

II December 2012

Number of times this article has been viewed

\section{Shunji Tomatsu' \\ William G Mackenzie' \\ Mary C Theroux' \\ Robert W Mason' \\ Mihir M Thacker' \\ Thomas H Shaffer' \\ Adriana M Montaño² \\ Daniel Rowan ${ }^{2}$ \\ William Sly ${ }^{3}$ \\ Carlos J Alméciga-Díaz ${ }^{4}$ \\ Luis A Barrera ${ }^{4}$ \\ Yasutsugu Chinen ${ }^{5}$ \\ Eriko Yasuda' \\ Kristen Ruhnke' \\ Yasuyuki Suzuki ${ }^{6}$ \\ Tadao Orii ${ }^{7}$}

'Nemours/Alfred I duPont Hospital for Children, Wilmington, DE, USA;

${ }^{2}$ Department of Pediatrics, ${ }^{3}$ Edward A Doisy Department of Biochemistry and Molecular Biology, Saint Louis University, St Louis, MO, USA; ${ }^{4}$ Institute for the Study of Inborn Errors of Metabolism, Pontificia Universidad Javeriana, Bogotá DC, Colombia; ${ }^{5}$ Department of Pediatrics, Faculty of Medicine, University of the Ryukyus, Okinawa, Japan; ${ }^{6}$ Medical Education Development Center, ${ }^{7}$ Department of Pediatrics, Gifu University, Gifu, Japan

Correspondence: Shunji Tomatsu Skeletal Dysplasia Center, Nemours Biomedical Research, Nemours/ Alfred I duPont Hospital for Children, 1600 Rockland Road, Wilmington, DE 19899-0269, USA

Tel +I 3022987336

$\mathrm{Fax}+|30265| 6888$

Email stomatsu@nemours.org
Abstract: Patients with mucopolysaccharidosis type IVA (MPS IVA; Morquio A syndrome) have accumulation of the glycosaminoglycans, keratan sulfate, and chondroitin-6-sulfate, in bone and cartilage, causing systemic spondyloepiphyseal dysplasia. Features include lumbar gibbus, pectus carinatum, flaring of the rib cage, marked short stature, cervical instability and stenosis, kyphoscoliosis, genu valgum, and laxity of joints. Generally, MPS IVA patients are wheelchair-bound as teenagers and do not survive beyond the second or third decade of life as a result of severe bone dysplasia, causing restrictive lung disease and airway narrowing, increasing potential for pneumonia and apnea; stenosis and instability of the upper cervical region; high risk during anesthesia administration due to narrowed airway as well as thoracoabdominal dysfunction; and surgical complications. Patients often need multiple surgical procedures, including cervical decompression and fusion, hip reconstruction and replacement, and femoral or tibial osteotomy, throughout their lifetime. Current measures to intervene in disease progression are largely palliative, and improved therapies are urgently needed. A clinical trial for enzyme replacement therapy (ERT) and an investigational trial for hematopoietic stem cell transplantation (HSCT) are underway. Whether sufficient enzyme will be delivered effectively to bone, especially cartilage (avascular region) to prevent the devastating skeletal dysplasias remains unclear. This review provides an overview of historical aspects of studies on MPS IVA, including clinical manifestations and pathogenesis of MPS IVA, orthopedic surgical interventions, and anesthetic care. It also describes perspectives on potential ERT, HSCT, and gene therapy.

Keywords: mucopolysaccharidosis IVA, keratan sulfate, GALNS, enzyme replacement therapy, gene therapy, hematopoietic stem cell transplantation

\section{Introduction}

Mucopolysaccharidosis type IVA (MPS IVA; Morquio A disease) is a rare autosomal recessive disorder caused by deficiency of $\mathrm{N}$-acetylgalactosamine 6-sulfate sulfatase (GALNS), a lysosomal enzyme. Breakdown of the glycosaminoglycans (GAGs), keratan sulfate $(\mathrm{KS})$, and chondroitin-6-sulfate (C6S) is partly dependent upon GALNS. Clinically, MPS IVA patients develop a characteristic spondyloepiphyseal skeletal dysplasia due to progressive storage of $\mathrm{KS}$ and $\mathrm{C} 6 \mathrm{~S}$. The reported incidence of MPS IVA varies: one in 200,000 live births in British Columbia and Australia, ${ }^{1,2}$ one in 76,000 live births in Northern Ireland, ${ }^{3}$ and one in 450,000 live births in The Netherlands and Portugal. ${ }^{4,5}$ The incidence for the United States population has not yet been reported.

Patients with MPS IVA appear normal at birth. MPS IVA varies from severe systemic bone dysplasia to a lesser form of the disease that includes only mild 
bone involvement. ${ }^{6,7}$ Patients with the severe form of the disease have a shortened lifespan, not usually surviving past their second or third decade. For mild MPS IVA, lifespan has been noted to be as long as 70 years. $^{7}$

MPS IVA patients usually require medical attention during the second or third year of life because of deformity of the spine (a lump on the lumbar spine - lumbar gibbus), deformity of the chest (pectus carinatum - sternal bulging, flaring of the rib cage), abnormal gait, short-trunked dwarfism, and/or genu valgum (Figure 1). Patients with a severe form may not survive past the second or third decade of life due primarily to cervical instability and stenosis and/or pulmonary compromise (respiratory infection and narrow airway). Typically, patients require a series of orthopedic surgeries (eg, cervical decompression and fusion, femoral or tibial osteotomy, hip reconstruction and replacement) throughout their lifetime. These procedures are complicated by major anesthetic risks due to progressive airway narrowing, elevated resistance to airflow, and potential pulmonary compromise due to thoracoabdominal dysfunction. ${ }^{6-8}$

The natural history of major clinical features in MPS IVA has not been elucidated. In 1998, an international Morquio A registry was started. Medical information from MPS IVA patients was collected by the nonprofit International Morquio Organization (Carol Ann Foundation; http://www.morquio.com).
By the end of April 2012, this database included information from more than 400 MPS IVA patients. The current Morquio A Registry database was the first to provide insights into MPS IVA disease and provided valuable information related to growth parameters, clinical signs and symptoms, and surgical procedures and frequency. ${ }^{7}$ A Morquio Tissue Repository Bank was also established at Nemours/Alfred I duPont Hospital for Children in 2011 and is expected to contribute to clarification of mechanisms of this disease.

GALNS is one of several enzymes required for the breakdown of GAGs (C6S and KS). KS synthesis occurs mainly in cartilage cells, ${ }^{9-11}$ and the deficiency of GALNS activity results in the accumulation of undigested $\mathrm{C} 6 \mathrm{~S}$ and $\mathrm{KS}$ in lysosomes of these cells, which leads to progressive skeletal dysplasia. ${ }^{72-14}$ Excessive undegraded $\mathrm{KS}$ is released into the circulation and is, thus, an important biomarker for characterizing MPS IVA. In healthy individuals, blood KS levels are very low at birth and then rise progressively during the first 4 years of life, remain elevated until 13 years of age, then decline rapidly until they stabilize around age $20 .{ }^{15,16}$ Endochondral ossification of cartilage is one of the essential processes during development of the mammalian skeletal system by which bone tissue is created. It is also an essential process during the formation of long bones and fracture healing. ${ }^{17-19}$

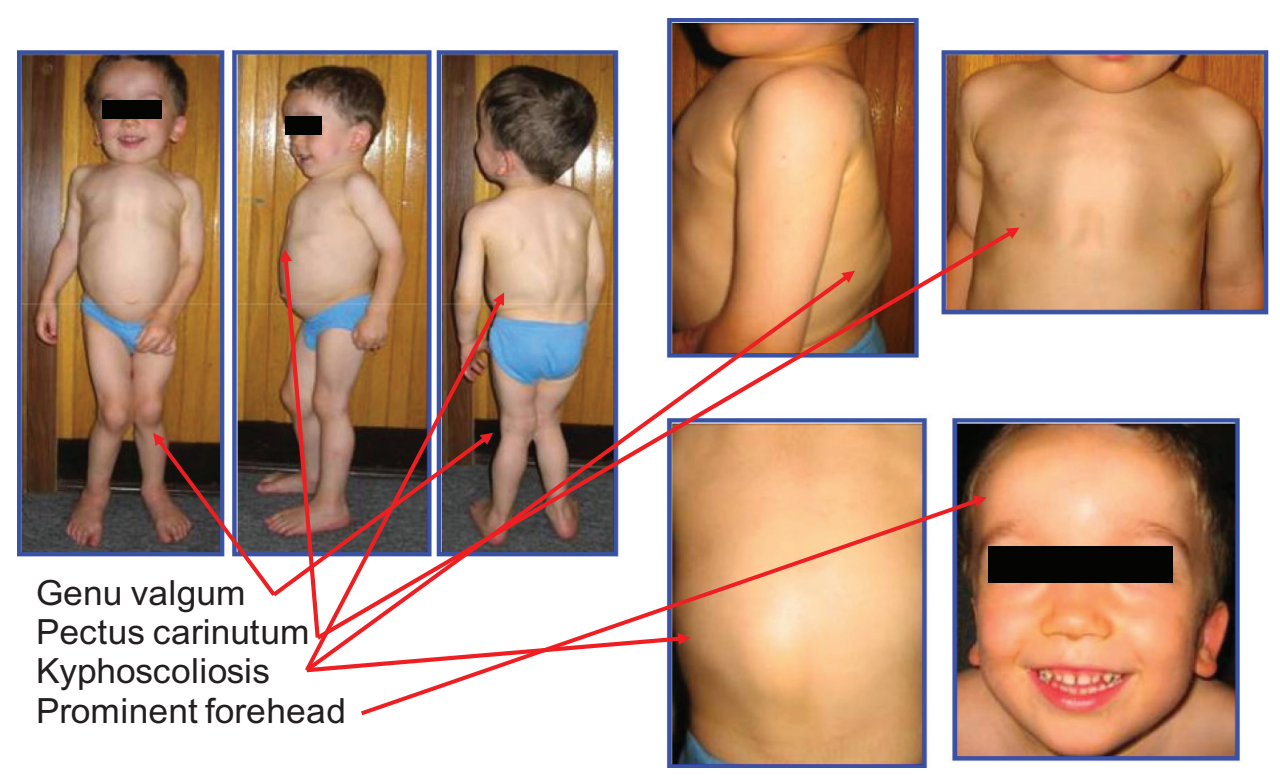

Figure I Clinical features of an MPS IVA patient.

Notes: The three-year-old patient in the figure had bone deformities (short stature, pectus carinatum, kyphoscoliosis, genu valgum, prominent forehead, and abnormal gait) (height $90 \mathrm{~cm}$, 50th percentile of male Morquio A growth chart; bodyweight $14 \mathrm{~kg}$ ). For patients with the attenuated form of the disease, the symptoms are not so prominent or clinically conspicuous in childhood and progress more slowly. Usually the first noticeable symptoms in a severe form of MPS IVA patients are bone deformity, abnormal gait (tendency to fall down), and hyperlaxity (knock-knee, floppy wrists, cervical instability). Later, most patients develop hearing loss, feasibility of infection, easy fatigue, and cervical myelopathy. Copyright (C) 2005, The Carol Ann Foundation and The International Morquio Organization. Images reproduced with permission from Slide 74. Educational CD for Morquio. Tucson, AZ: The Carol Ann Foundation and The International Morquio Organization; 2005. ${ }^{87}$

Abbreviation: MPS IVA, mucopolysaccharidosis type IVA. 
Decline of blood KS levels after 13 years of age is consistent with the fact that the growth rate in healthy children decreases during the teen years. In MPS IVA patients, blood KS levels are high at birth and peak between 5 and 10 years of age, while urine KS levels peak between ages 0 and 5. ${ }^{20-22}$ Blood and urine KS levels are higher in MPS IVA patients than in age-matched controls up to the age of 20 years. Although plasma KS levels tend to normalize by age 20, urine KS levels remain higher in MPS IVA patients than controls after 20 years of age..$^{15,20,22}$ Analysis of blood and urine KS concentrations is a useful tool for assessing the clinical status of patients with MPS IVA. It will also be appropriate for assessing response to treatments like enzyme replacement therapy (ERT), hematopoietic stem cell transplantation (HSCT), and gene therapy.

Currently, no medications have been approved to prevent or treat the progression of MPS IVA disease. However, supportive measures are often provided. For joint pain, patients are given nonsteroidal anti-inflammatory drugs, and antibiotics are prescribed for otolaryngology infections. Patients are given oxygen to treat pulmonary restriction issues. Surgical procedures are often required throughout life, including adenoidectomy, tonsillectomy, cervical decompression and fusion, and corrective hip surgery for dysplasia and knee surgery for genu valgum deformity. Since many patients with MPS IVA have extradural collections of GAGs causing stenosis and odontoid hypoplasia resulting in atlantoaxial subluxation, physicians recommend cervical spine fusion/decompression surgery for most affected patients. In preclinical trials with mouse models of MPS IVA, recombinant bone-targeting human GALNS enzyme was more effective when compared with untagged native GALNS. ${ }^{23,24}$ Gene therapy with bone-targeting Adenoassociated virus (AAV) vectors is being evaluated in an MPS IVA mouse model.$^{25}$ Human clinical trials using ERT for MPS IVA with an untagged native enzyme and investigational trials for HSCT are in progress. ${ }^{7}$

In this review, the historical aspects, pathogenesis, orthopedic surgical procedures, anesthesia care, ERT, HSCT, and gene therapy for MPS IVA are described. These experimental procedures and treatments may provide a better quality of life by ameliorating the underlying disease progression of MPS IVA and consequently prevent further damage of targeted organs and reduce risks associated with additional surgical procedures.

\section{History of MPS IVA study}

Table 1: L Morquio, a pediatrician in Uruguay, first described mucopolysacchariosis type IVA (MPS IVA; Morquio A;
OMIM 253000) in four Swedish siblings in 1929; in that same year, it was also described independently by JF Brailsford in England. ${ }^{6,26}$ Prominent forehead, accentuated lower portion of the face, short neck, barrel chest with sternal bulging, flaring of the rib cage, knock-knees, ligamentous laxity, short-spine dwarfism, and flat feet were clinical features noted by Morquio; ${ }^{6}$ however, he did not document corneal clouding and aortic valve disease features of MPS IVA.

In 1962, Pedrini et al reported urinary excretion of KS in MPS IVA patients. ${ }^{27}$

In 1971, Orii et al reported a milder (intermediate) form of MPS IVA. ${ }^{28}$ At 5 months of age, adduction of both thumbs was noticed, and at 18 months of age, a chest abnormality was recognized. At the age of 3 years, kyphosis was present, and the patient had an abnormal gait by the age of 5 years old. The subject had keratosulfaturia and was diagnosed enzymatically as MPS IVA at age 15. At the age of 18 years, the patient was $135 \mathrm{~cm}$ tall and manifested the milder skeletal deformities like pectus carinatum, genu valgum, hypermobile joints, and corneal clouding.

In 1981, Orii et al described a very mild form of MPS IVA in two siblings. ${ }^{29}$ The elder brother was $147 \mathrm{~cm}$ and the younger brother $157 \mathrm{~cm}$ tall at final heights. Their initial symptom was hip joint pain at the age of 8 years, and thus both were managed by femoral osteotomy at age 13 years. Both cases had keratosulfaturia, corneal clouding, and mild thorax changes; although, they did not have unique pectus carinatum, genu valgum, excessive joint laxity, or facial changes. Initial radiographic studies on both cases revealed mild platyspondyly, slight anterior wedging of the lumbar vertebra, and minimal odontoid hypoplasia, as well as subtle capital femoral epiphyses. However, when the two brothers were aged 18 and 22, the ossified femoral heads had disappeared with erosion and widening of the femoral necks. These signs were more marked in the older brother. GALNS activity in patient fibroblasts was about $10 \%$ of that seen in cells from normal healthy controls. ${ }^{30}$

MPS IVA varies from severe systemic bone dysplasia to a lesser form of the disease that includes only mild bone involvement. ${ }^{7,28-31}$ The severe form of the disease has shortened lifespan not usually past the second or third decade. For mild MPS IVA, lifespan has been noted to be as long as 70 years. ${ }^{7,12}$

Molecular analysis, pathogenesis, and development of innovative therapies for MPS IVA were promoted after purification of human GALNS ${ }^{32}$ cloning and characterization of the human GALNS gene, ${ }^{33,34}$ identification of mutations, ${ }^{35-37}$ and cloning of the mouse gene..$^{38}$ About 180 different mutations 
Table I History of MPS IVA study

\begin{tabular}{|c|c|c|c|}
\hline Year & Description & First author(s) & Ref \\
\hline 1929 & First description of MPS IVA patients in Uruguay and England & Morquio L; Braisfold J & 6,26 \\
\hline 1962 & Isolation and identification of keratosulfaturia & Pedrini $V$ & 27 \\
\hline 1971 & Intermediate type of MPS IVA patient & Orii T & 28 \\
\hline 1974 & Identification of defective enzyme in MPS IVA & Matalon R & 80 \\
\hline 1978 & Assay method of $\mathrm{N}$-acetyl-galactosamine-6-sulfate sulfatase & Glossi J & 81 \\
\hline 1978 & Defect of galactosamine-6-sulfate sulfatase & DiFerrante $\mathrm{N}$ & 82 \\
\hline 1981 & Mild type of MPS IVA patients & Orii T & 29 \\
\hline 1991 & Purification of GALNS and preparation of the antibody & Masue M; Bielicki J & 32,83 \\
\hline 1991 & Cloning of human cDNA & Tomatsu S & 33 \\
\hline 1992 & First identification of mutations in classical and mild types & Fukuda S & 35 \\
\hline 1992 & Chromosomal localization & Tomatsu S & 84 \\
\hline 1994 & Cloning of human genomic gene & Nakashima $Y$ & 34 \\
\hline 1995 & Common mutation & Tomatsu S & 36 \\
\hline 1998 & Establishment of International Morquio Registry & International Morquio Organization and Carol Ann Foundation & \\
\hline 2000 & Cloning of mouse gene & Montaño AM & 38 \\
\hline 2000 & Tertiary structure of GALNS & Sukegawa K & 42 \\
\hline 2001 & Retroviral gene therapy in vitro & Toietta G & 68 \\
\hline 2003 & MPS IVA murine model & Tomatsu S & 43 \\
\hline 2004 & $\mathrm{KS}$ assay by ELISA & Tomatsu S & 15 \\
\hline 2005 & Educational CD for Morquio & International Morquio Organization and Carol Ann Foundation & \\
\hline 2005 & Mutation update & Tomatsu S & 39 \\
\hline 2007 & Recombinant human GALNS produced in $\mathrm{CHO}$ & Tomatsu S, Montaño AM and Gutierrez M & 41 \\
\hline 2007 & $\mathrm{KS}$ assay by tandem mass spectrometry & Oguma S & 85 \\
\hline 2007 & Description of International Morquio Registry & Montaño S & 12 \\
\hline 2007 & ERT on adult MPS IVA KO mouse & Tomatsu S and Montaño AM & 23 \\
\hline 2008 & Growth chart of Morquio A patients & Montaño S & 13 \\
\hline 2010 & ERT with bone-targeting on MPS IVA mouse & Tomatsu S, Montaño AM and Dung VC & 24 \\
\hline 2010 & $A A V$ gene therapy in vivo & Almeciga-Diaz CJ & 25 \\
\hline 2011 & Morquio Tissue Repository Bank & Tomatsu S and Mackenzie W & $\begin{array}{l}\text { unpublished } \\
\text { data }\end{array}$ \\
\hline
\end{tabular}

of GALNS have been identified. ${ }^{39,40}$ Production of recombinant human GALNS in CHO cells ${ }^{41}$ allowed purification of human GALNS, identification of the three-tiered structure of GALNS, ${ }^{42}$ and provided enzyme for experimental ERT. Three mouse models for MPS IVA ${ }^{43-45}$ were developed to study pathogenesis and experimental ERT. Development of KS assays using enzyme-linked immunosorbent assay or liquid chromatography/tandem mass spectrometry have facilitated diagnosis and screening (Table 1). ${ }^{15,20-22}$ Genotype/phenotype correlations have been identified for some of the mutations. The International Morquio Registry ${ }^{12}$ has provided growth charts for MPS IVA patients. ${ }^{13}$

\section{Current and emerging treatments for MPS IVA$$
\text { Orthopedic surgical procedures }
$$

Initial surgical procedures are often required for MPS IVA patients at a mean age of 7 years. These procedures include adenoidectomy and tonsillectomy and placement of myringotomy tubes. These patients also often require more extensive surgeries in the leg, knee, hip, and neck at a mean age of 10 years. ${ }^{12}$ About half of teenagers with MPS IVA are already limited to wheelchairs for mobility. ${ }^{12}$

\section{Upper spine}

Odontoid hypoplasia, ligamentous laxity, incomplete ossification of the anterior and posterior rings of the atlas, and anterior extradural space deposition of GAGs are believed to be the cause of spinal cord compression and atlantoaxial instability $;^{7}$ a high incidence is reported in this population (Figure 2). Cervical myelopathy, quadriparesis, or death may result from atlantoaxial subluxation and compression of the spinal cord. In patients with MPS IVA, exercise intolerance may mean unidentified cervical myelopathy is present. Bowel and bladder dysfunction may result. Spinal cord compression is often evident on magnetic resonance imaging (MRI) at the craniocervical junction, as is deposition of storage materials on the tip of the odontoid process (Figure 3).

Untreated upper cervical stenosis and instability can cause irreversible damage to the spinal cord. Atlantoaxial instability and subsequent cervical myelopathy are the main cause of mortality and morbidity. ${ }^{7}$ Even a minor injury to the neck 


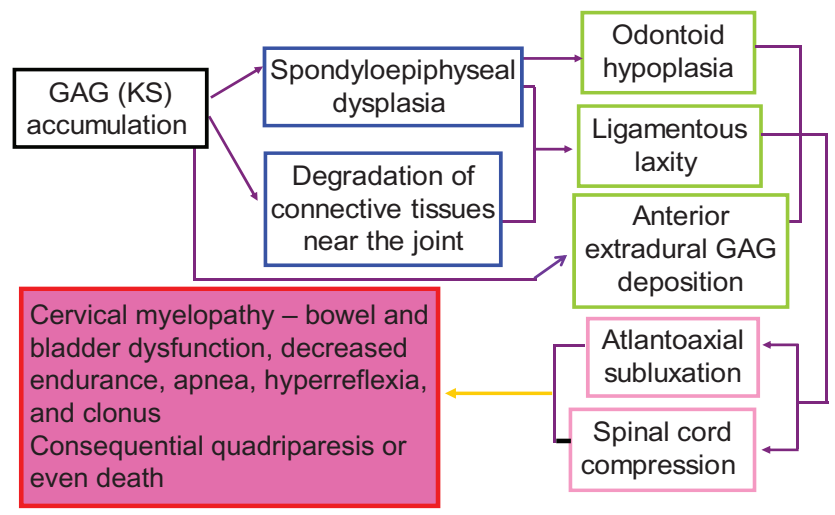

Figure 2 Hypothesis of pathogenesis of cervical instability and cervical spinal cord compression.

Notes: Spinal cord compression is the most critical key feature to recognize in MPS IVA patients. Odontoid hypoplasia, ligamentous laxity, and extradural GAG deposition, can result in atlantoaxial subluxation with cord compression, leading to cervical myelopathy. A history of exercise intolerance in patients with MPS IVA often predicts the presence of occult cervical myelopathy, which can also cause bowel and bladder dysfunction and weakness or paralysis. Mortality and morbidity rates are primarily related to the atlantoaxial instability and subsequent cervical myelopathy. Severely affected patients, primarily related to cervical instability, often do not survive beyond the second or third decade of life.A minor fall or extension of the neck can result in cord transection and subsequent quadriparesis or sudden death. Copyright (C) 2005 The Carol Ann Foundation and The International Morquio Organization. Reproduced with permission from Slide 53. Educational CD for Morquio. Tucson, AZ:The Carol Ann Foundation and The International Morquio Organization; $2005 .{ }^{88}$

Abbreviations: GAG, glycosaminoglycan; KS, keratan sulfate; MPS IVA, mucopolysaccharidosis type IVA.

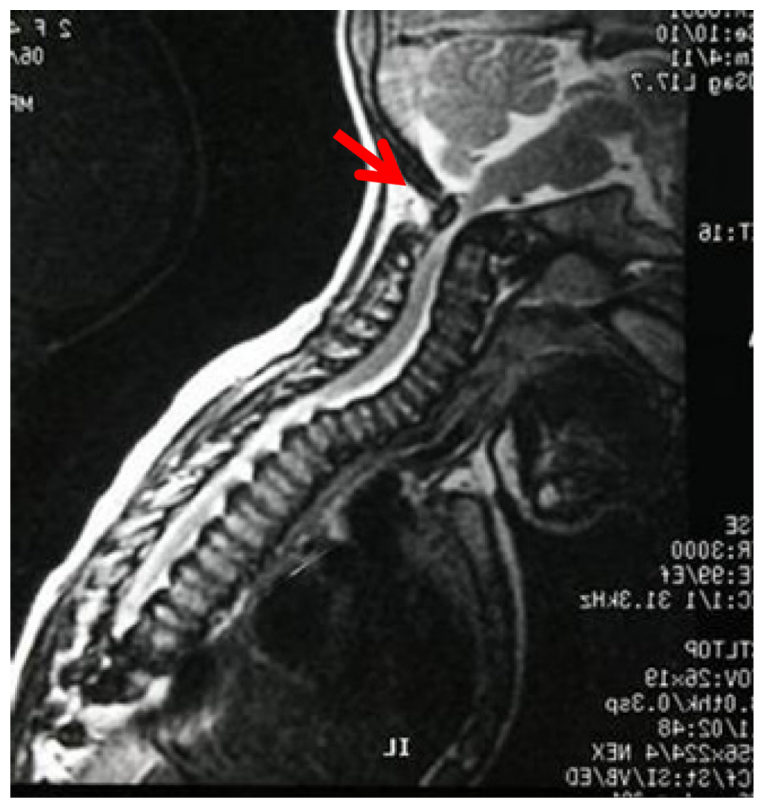

Figure $3 \mathrm{MRI}$ image of cervical spine in an MPS IVA patient aged 3 years.

Notes: The arrow shows the spinal cord compression. A baseline study of the upper cervical anatomy is recommended no later than 2 years or at diagnosis using flexion/extension X-ray films. If pain associated with weakness or tremors (clonus) in the arms or legs occur, the patient should have studies of the neck to evaluate for the slippage (subluxation) of the neck vertebrae and compression of the spinal cord. $X$-rays and MRI will be taken with neck flexed and extended and will be monitored annually to check the situation.

Abbreviations: MPSIVA, mucopolysaccharidosis type IVA; MRI, magnetic resonance imaging. can cause damage to the spinal cord, which could then lead to paralysis or even be quickly fatal.

Cervical compression should be evaluated by cervical flexion-extension lateral views and cervical MRI or computed tomography (CT), and aggressively treated in MPS IVA patients. Imaging by the age of at least 2 years (MRI and radiographs) is important. Patients should then be followed annually to determine whether surgery will be required. Early fusion, with or without decompression, is recommended to correct the instability and prevent permanent damage to the spinal cord.

Stabilization of the cervical spine may be accomplished using internal fixation supplemented by halo-vest stabilization as needed. Fusion is usually achieved with autologous bone graft from the iliac crest, tibia (historical), or ribs. Halo immobilization during and after the spinal cord compression/fusion procedure has provided satisfactory results, even in very young patients (Figure 4). The os odontoideum tends to ossify after successful upper cervical fusion. It remains unanswered why this does not take place in the unfused cervical spine. The extradural deposition surrounding the cervical cord region also tends to resolve once stability is attained. The upper cervical fusion procedure is safe and effective in patients affected by MPS IVA to fix upper cervical instability and neurological involvement. Careful long-term observation is advocated for early diagnosis and management of late complications (instability below the fusion level) and a second area compression lower down in the spine.

\section{A 4 years old (post cervical fusion)}

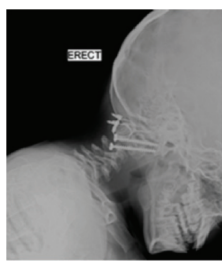

Flexion

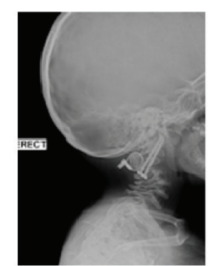

Neutral

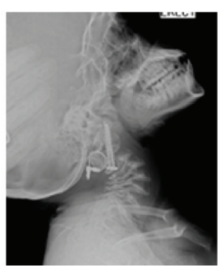

Extension
B 2.5 years old (halo-vest)

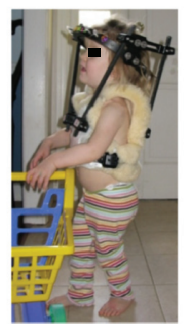

Figure 4 Post-cervical fusion operation. (A) $\mathrm{Cl}-\mathrm{C} 2$ stability has been achieved with internal fixation and bone grafting. (B) Postoperative immobilization in children for whom stability cannot be achieved is managed with a halo vest. 


\section{Hip surgery}

The hips are either normal or slightly subluxated in patients with MPS IVA. The capital femoral epiphyses are smaller than normal and progressively flatten and may become fragmented over time. There is widening of the femoral neck in adulthood. Progressive proximal and lateral subluxation of the femoral heads occurs over time, finally resulting in frank dislocation if no intervention is carried out. The proximal femurs are in valgus in most patients. The acetabulum is to some extent shallow when compared with normal acetabulum initially and becomes gradually more dysplastic with subluxation of the hip. The acetabular deficiency is mostly antero-superior as noted in a computed tomography scan study. ${ }^{46,47} \mathrm{~A}$ false acetabulum is often seen when the hips are dislocated. A saddle-shaped femoral head may ultimately be observed at skeletal maturity. Surgery is often needed in these patients to preserve the hip joint. Proximal femoral varus and derotation osteotomies and procedures to improve acetabular coverage such as a shelf arthroplasty can stabilize the hip and improve gait mechanics. ${ }^{48}$ Recurrent hip deformity is common if the hips are not properly contained. Joint replacement surgery in adults may be needed in cases with severe arthritis and pain. The abnormal anatomy makes hip replacement challenging.

\section{Knee surgery}

Patients with MPS IVA develop a progressive genu valgum with involvement of the distal femur as well as proximal tibia and joint laxity. This can interfere with walking ability and often needs surgical intervention. There are a variety of surgical procedures described for their correction, including growth modulation, acute correction with osteotomies, and gradual correction with external fixators for larger deformities. Recurrent deformities are common. Articular cartilage damage may be seen, similar to the changes in the femoral head.

\section{Anesthetic care}

MPS IVA patients are a high risk population for anesthetics; careful consideration is required to prevent morbidity and mortality during procedures. ${ }^{49}$ Anesthetic care of these patients should preferably be in centers staffed with pediatric anesthesiologists experienced in this disorder. The most important anesthetic complications related to MPS IVA are as follows.

\section{Airway management}

MPS IVA patients have instability and stenosis of the cervical spine $(\mathrm{C} 1-\mathrm{C} 2)$ often associated with cervical cord compression. During intubation, care must be taken to limit movement of the neck to avoid sudden nerve damage. Head and neck need to be kept in neutral position during intubation, minimizing flexion/extension of the neck. MPS IVA patients often have an unfavorable airway for ventilation (high resistance to airflow), with face mask as well as intubation of the trachea and the need for minimizing head and neck movements an added burden on the anesthesiology staff when caring for these patients. When the level of concern for spinal cord compromise is high enough, it is advisable to monitor evoked potentials during intubation to assess spinal cord integrity during intubation maneuvers. Depending on the degree of instability, manual in-line stabilization of the head and neck might be sufficient to protect the spinal cord from excessive movements of the head and neck during intubation (Figure 5). MPS IVA patients have restricted airways due to multiple factors: large tongue, short neck, sub-mucosal and cartilaginous GAG deposits, and decreased mobility of the head and neck all contribute to make ventilation and intubation difficult. Difficult-airway tools that displace soft tissue easily are preferable in MPS IVA patients. ${ }^{50}$
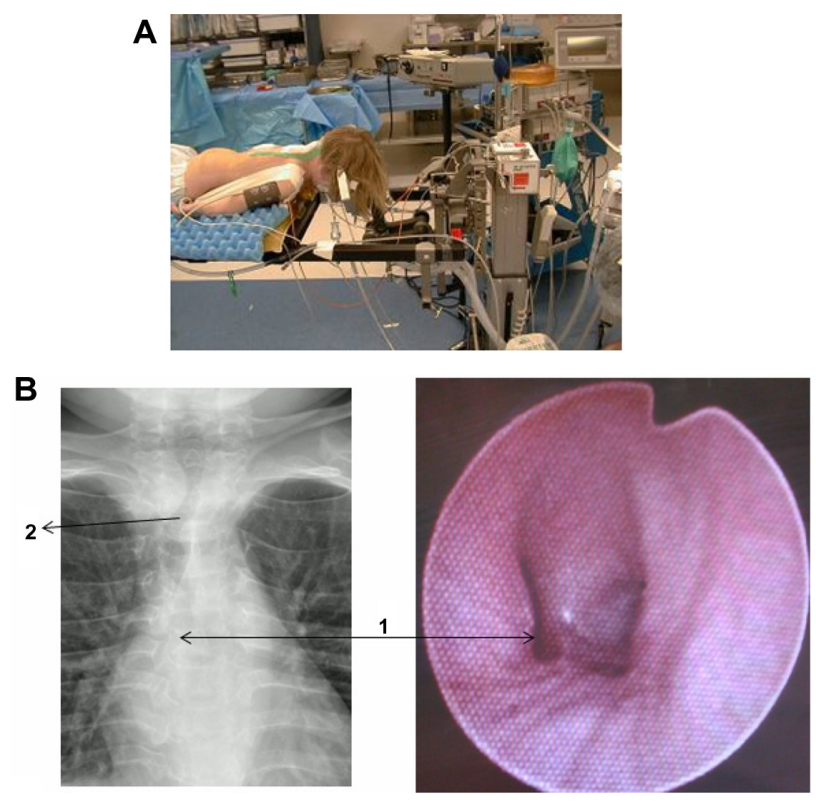

Figure 5 Anesthesia care of MPS IVA patient. (A) Head and neck stabilization (fixation) during surgery to achieve the most stable cervical spine alignment. The position of the head in relationship to the neck is very important here. Head should be positioned in slight extension in order to facilitate optimal patency and unobstructed breathing. (B) Chest X-ray showing tortuous trachea and bronchi in a patient with MPS IVA (left) Fiberoptic bronchoscope showing the distorted appearance of the carina and left bronchus in the same patient (right).

Notes: The tortuous and redundant trachea with buckling of main trachea easily possible with change in head and neck position. Arrow I shows the stretched and abnormally shaped lumen of the left bronchus. Arrow 2 shows the redundancy and buckling of the main trachea.

Abbreviation: MPS IVA, mucopolysaccharidosis type IVA. 
Equipment classified as video laryngoscopes are most suited for these patients. A video laryngoscope called AVIL (angulated video-intubation laryngoscope) had been used as early as $2001^{51}$ to successfully intubate children while using in-line stabilization and minimization of cervical movements. ${ }^{52}$ While the Glidescope (Verathon Inc, Bothell, WA) is the most frequently successful difficult intubation tool in our hands, it is unlikely to be successful in all patients with MPS IVA. When the Glidescope fails to intubate the trachea of a patient, the contributing factors (short neck, fused cervical vertebrae, and large tongue) are common to the features of MPS IVA patients. ${ }^{52}$ To improve the success rate, a simple and effective maneuver in any patient with a large tongue is displacing the tongue anteriorly before Glidescope insertion, using any convenient device such as Magill forceps or ring forceps or simply a piece of gauze. This will significantly enhance visualization of the larynx. Placing tongue sutures to retract the tongue is another option but is more invasive ${ }^{53}$ and not usually opted for by anesthesiologists.

MPS IVA patients also often require a smaller endotracheal tube than expected due to difficulty passing the tube down the smaller than anticipated airway.

Abnormalities of the airway include structural abnormalities of the trachea and bronchi. Pulmonary and otolaryngological evaluations prior to surgery and anesthesia are recommended. ${ }^{8,54}$ In addition, the trachea and bronchi were evaluated using a fiberoptic bronchoscope following intubation to assess patency and continuity of tracheal lumen. Abnormalities of the tracheal or bronchial lumen are not uncommon even when a patient is completely asymptomatic (Figure 5). This additional step further helps with plans for extubation.

Theroux et al recently examined 28 children with MPS IVA and their perioperative anesthetic care and made the following recommendations: ${ }^{55}$

1. Airway evaluation in patients with MPS IVA, not only to intubate the trachea, but also to facilitate optimal head and neck position for postoperative care.

2. Otolaryngological consultation to document abnormalities of airway and pulmonary consultation to evaluate respiratory function.

3. Use of the video laryngoscope as the tool of first choice when intubating patients, especially a patient who has a prior cervical fusion and/or anticipation of difficulty with direct laryngoscopy.

4. Awareness that some patients will be very difficult to intubate, regardless of choice of equipment.
5. When patient has significant risk due to spinal cord compromise from an unstable cervical spine, use of evoked potential monitoring during intubation of the trachea will provide information to avoid injury from head and neck movements during intubation.

6. Manual displacement of the tongue anteriorly during intubations.

7. Expectation of difficulty with nasal fiber-optic bronchoscope due to narrow nasopharyngeal path.

8. Cardiac consultation to evaluate structural and functional abnormality.

\section{Attention to recovery from anesthesia of MPS IVA patients}

Only awake extubation provides sufficient evidence to maintain spontaneous and adequate respiration without stimulation. It also provides the physician the chance to assess obeying of commands such as "take a deep breath." Watching for abnormalities of respiratory movements as the patient is emerging from anesthesia and being ready to evaluate the etiology for such abnormalities by examining with a fiber-optic bronchoscope is recommended. There may be transient paradoxical chest movement due to localized trachea or laryngomalacia, of which, most will resolve when residual anesthetics are eliminated. Patient ability to maintain their head and neck in the optimal position similar to preoperative status is also important and is aided by an awake patient. Skilled airway personnel should be available and ready to reintubate the patient should it become necessary. Tracheotomies are difficult, especially when done in an emergency, due to anatomical abnormalities such as short neck, pectus carinatum, and the redundant and buckling trachea.

\section{Hematopoietic stem cell transplantation (HSCT)}

A potential advantage of HSCT for treating lysosomal storage diseases (LSDs) is that marrow-derived donor macrophages could provide a secreting source of enzyme and gain access to various storage sites. HSCT has successfully corrected the disease course and severity in patients with a severe form of MPS I or with MPS VI. ${ }^{56,57}$ The clinical consequence of HSCT relies on (1) the age of the patient at the time of transplantation, (2) the severity of clinical phenotype, (3) the type of donor, and (4) the course of preparative regimen. ${ }^{58}$ In MPS I and VI patients, HSCT results in maintained normal heart function and hearing is improved. However, skeletal manifestations develop progressively, and corneal clouding 
is not diminished. Therefore, HSCT of MPS IVA patients may not have a positive impact on the skeletal system. There are only a few reports of HSCT for MPS IVA patients, and none have described detailed clinical consequences of HSCT. The authors of this present paper examined a male MPS IVA patient before and after successful allogeneic bone marrow transplantation $(\mathrm{BMT})^{7}$ (and: Chinen et al, personal communication, August, 2011). Five years after BMT, GALNS activity was restored in the lymphocytes, the patient showed (1) improvement of motor function (recovery of ambulatory) in combination with osteotomies; (2) disappearance of shortage of breath at motion (remission of narrow airway); (3) vanishing of snoring; (4) improvement of glaucoma; and (5) increase of bone mineral density (Figure 6). After osteotomies of both femurs, the patient became ambulatory, walking $400 \mathrm{~m}$ without aid, although restriction of physical activity and hyperlaxity of joints remain unsolved. The substantial clinical correction post-BMT in this MPS IVA patient demonstrates that HSCT is a therapeutic option for MPS IVA patients. Additional BMT cases of MPS IVA are needed to determine whether the regimen of BMT adopted for this patient will be effective for other MPS IVA patients. The authors anticipate that if HSCT is performed for MPS IVA patients at an earlier stage, skeletal deformities, restrictive and obstructive airway, and impaired growth development should be ameliorated. Although regimens for HSCT have been revised in recent years, the procedure may still carry a high risk of mortality by infection, graft-versus-host
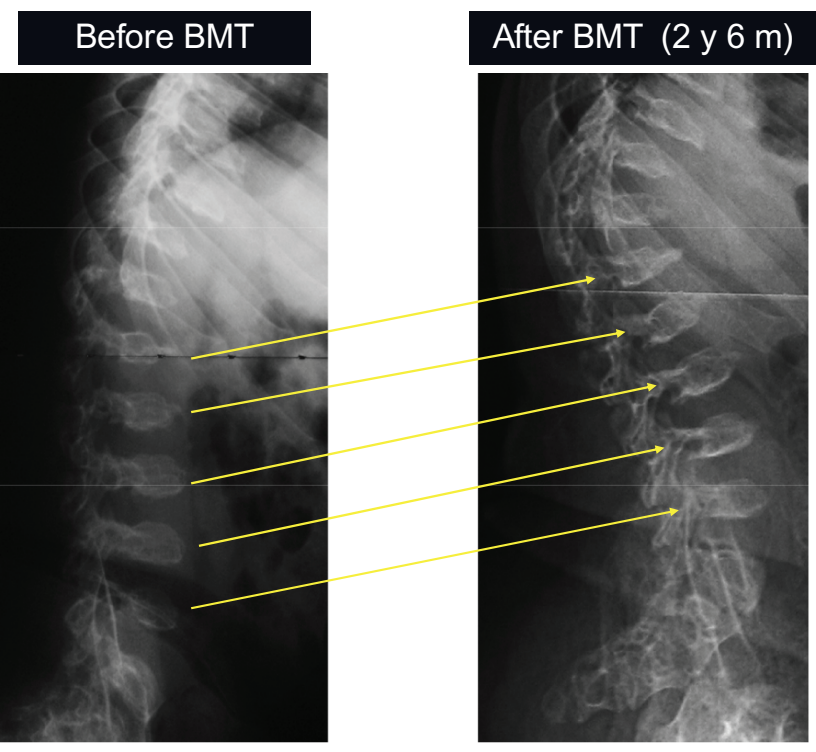

Figure 6 X-ray photographs of a lateral view of thoracolumbar vertebra before BMT and 2.5 years after BMT.

Note: Platyspondylia and anterior beaking of thoracolumbar vertebra increased slightly in size and the margin of vertebra became clear.

Abbreviation: BMT, bone marrow transplantation. disease, and additional complications. Thus HSCT should be considered in selected cases with careful pre-transplantation counseling and clinical evaluation, and with systemic longitudinal monitoring of the outcome.

\section{ERT}

Most of the enzymes infused are delivered and consumed by the major visceral organs such as liver, kidney, and spleen, and only a small amount of enzyme is delivered to bone. Most lysosomal enzymes have a short half-life in the circulation due to rapid binding to carbohydrate-recognizing receptors and uptake into these visceral organs. A small fraction of enzyme can reach the bone marrow, and even less enzyme reaches avascular cartilage cells. ${ }^{59}$ Improvement of bone lesions in Gaucher, ${ }^{60}$ MPS I, and MPS VI ${ }^{61}$ patients by ERT is limited, even after long-term treatment. Therefore, current conventional ERTs that target enzymes to carbohydraterecognizing receptors may not function efficiently on bone and cartilage lesions. Nevertheless, ERT using recombinant human native GALNS is currently in a Phase III clinical trial for MPS IVA patients. The native GALNS protein has mannose-6-phosphate (M6P) residues on its oligosaccharide chains, and consequently it is likely to be taken up into cells by the M6P receptor and delivered to lysosomes where it can catabolize accumulated GAGs. The authors anticipate that efficacy of therapy will be limited, at least initially, because there is little visceral organ involvement in MPS IVA patients. Careful long-term observations will be required to determine whether limited enzyme delivery to bone and cartilage will be sufficient to improve outcomes for these patients. The response to ERT is likely to depend on the age of the patient when treatment is initiated and the severity of the clinical condition. After several weeks of intravenous infusion, most patients have shown reduced levels of $\mathrm{KS}$ in urine, but levels of KS in blood have not yet been reported. After 3 months of ERT in MPS IVA mice, there is little impact on bone pathology. ${ }^{23}$ Therefore the reduction of urine KS seen in treated human MPS IVA patients may not predict improvement in either bone pathology or chondrocyte function at least in the short term. There may be a clinical effect of ERT by reducing the proinflammatory factors that are induced when excessive $\mathrm{KS}$ results in an abnormal structure of extracellular matrix, relieving arthritis and pain in joints, enabling an increase in physical activity, as described in other types of MPS. ${ }^{62}$ ERT with native enzyme could also improve hearing, reduce recurrent infection, and reduce airway narrowing (if the storage materials are released from the cartilage of the airway). While ERT with native enzyme may benefit some MPS IVA patients by arresting some aspects of disease progression, 
the fundamental problems associated with advanced skeletal deformity and laxity of joints are unlikely to be solved by current ERT with native enzyme.

To solve these intrinsic issues, an alternative approach has been developed to combine ERT with a bone targeting strategy (Figure 7). Hydroxyapatite (HA) is a major inorganic matrix of bone that is absent in soft tissues. Drugs that attach to HA will be released in the process of the bone resorption, and thereby targeting a drug to HA is a potential method for a selective drug delivery to bone. Estradiol attached to $\mathrm{Glu}_{6}$ (E6) is targeted to bone and helps prevent osteoporosis. ${ }^{63,64}$ The authors of this present paper and others have recently attached this novel bone-targeting peptide to an enzyme (tissue nonspecific alkaline phosphatase) and shown that the tagged enzyme is delivered more specifically to bone than unmodified enzyme, improving the clinical and pathological consequence of the systemic bone disease, hypophosphatasia. ${ }^{65,66}$ Human GALNS has also been bioengineered to add a hexa-glutamate sequence (E6) to its N-terminus (E6-GALNS). This tagged enzyme has a markedly reduced rate of clearance from the circulation, increasing blood levels 20 times higher than that of the untagged enzyme. The bone-targeting enzyme was retained longer in bone, with substantial residual enzyme activity. The pathological features in MPS IVA mice treated with the targeting enzyme show marked clearance of the storage materials in bone, especially after once-weekly injections for 24 consecutive weeks. These findings suggest that using the tagged enzyme enhances delivery and pathological effect in MPS IVA mice. ${ }^{24}$

\section{Gene therapy}

Gene therapy is the rational approach for treating skeletal diseases at an early stage, and animal research on other types of MPS is promising. Selection of vector, use of immunosuppressive drug, and route of administration should be addressed before the first human clinical trials are executed. ${ }^{25,67}$ The first study of gene therapy for MPS IVA was carried out by using a retrovirus vector. ${ }^{68}$ The retroviral vector carrying the human GALNS cDNA has been used for transduction of fibroblast and lymphocytes from unaffected and MPS IVA individuals, human keratinocytes, mouse myoblasts, and rabbit synoviocytes. GALNS enzyme activity levels between 5- and 50-fold higher than those observed in normal nontransduced cells have been observed, which leads to a reduction of intracellular GAG to normal levels. Although these results are promising, the report of side effects observed on patients that receive cells transduced with a retrovirus vector ${ }^{69}$ led to the evaluation of a different gene therapy vector.

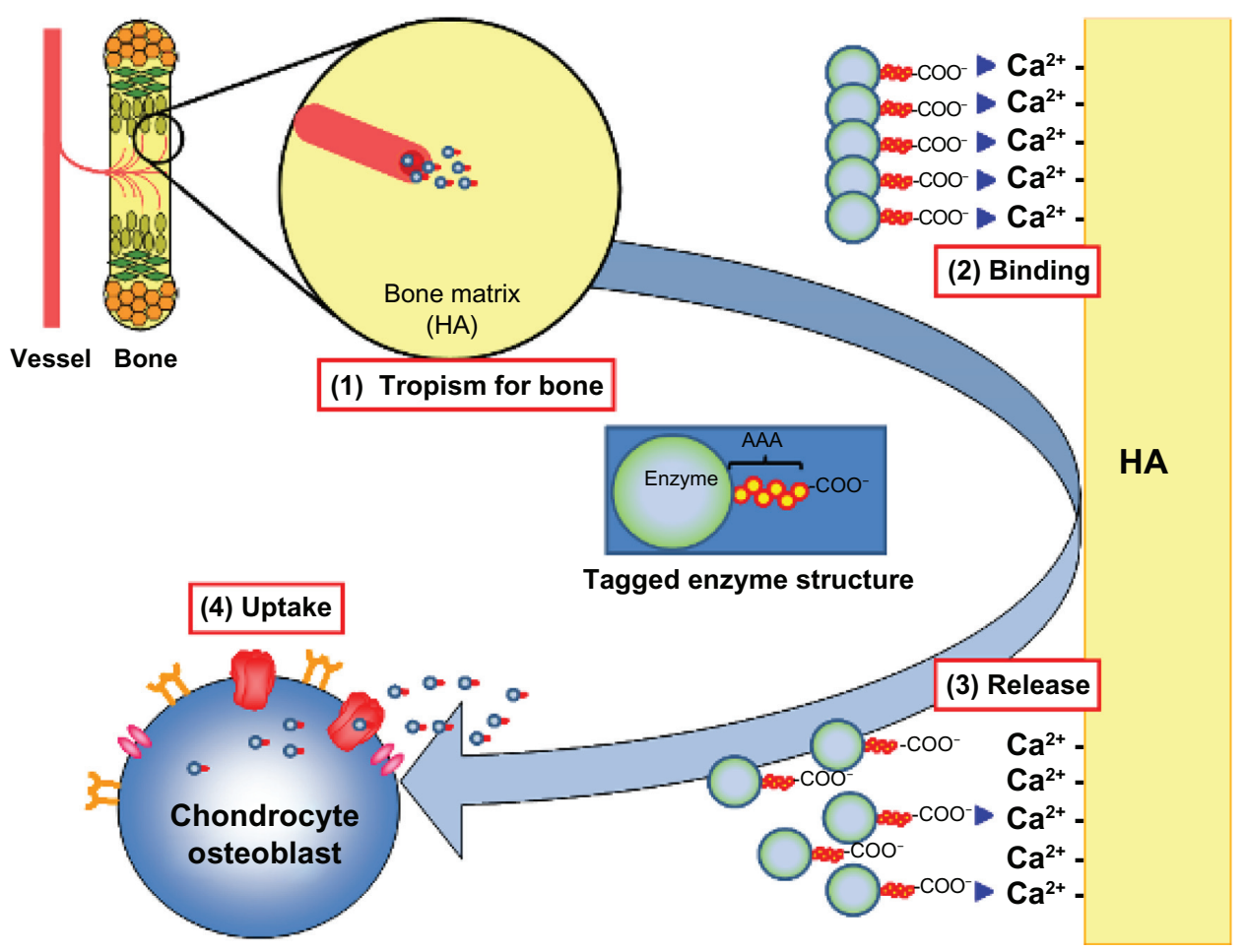

Figure 7 Mechanism of bone-targeting system.

Notes: Negatively-charged AAA-tagged enzyme will circulate in blood for longer time and (I) will be delivered to bone more efficiently, (2) will bind with calcium sites on $\mathrm{HA}$, (3) will be released from HA by proteolytic process, and (4) will be taken up by the receptor-mediated pathways.

Abbreviations: AAA, triple adenine; HA, hydroxyapatite. 
The AAV vector has been used because it has several merits such as a long-term expression, well characterized serotypes, wide-ranged cell and tissue tropism, and low immunogenicity. ${ }^{70-72}$ Moreover, AAV vectors have been used preclinically for more than 30 various metabolic disorders, half of which are LSDs, leading to marked correction of phenotype or improvement of biochemical features without side effects. ${ }^{70}$

In the first study, it was shown that AAV vectors could be used for the gene delivery of GALNS gene into MPS IVA fibroblasts and HEK293 cells, allowing significant increase in GALNS enzyme levels. ${ }^{67}$ The cytomegalovirus (CMV) promoter was used to mediate the expression of the transgene; however, there are the limitations of this promoter for gene therapy. ${ }^{73}$ To evaluate new promoters, the eukaryotic elongation factor $1 \alpha$ (EF1) and the $\alpha 1$-antitrypsin (AAT) promoters were tested. AAT and EF1 promoters allowed similar GALNS enzyme activity levels to those observed with CMV promoter in HEK293 cells, human MPS IVA fibroblasts, and murine MPS IVA chondrocytes. ${ }^{25}$ Also tested were the effects of co-transduction with sulfatase modifying factor 1 (SUMF1) on GALNS activity levels. In-vivo studies have shown that the co-expression of other sulfatases with SUMF1 induces a significant elevation of GALNS enzyme activity. ${ }^{747}$ However, the optimal ratio between the individual sulfatase and SUMF1 has not been fully investigated. The GALNS gene was transduced with or without SUMF1 into HEK293 cells, human MPS IVA fibroblasts, and mouse MPS IVA chondrocytes using AAV2 vectors. Enzyme expression was maintained for at least 10 days post-transduction, regardless of promoter used. Transduction of mouse MPS IVA chondrocytes recovered $70 \%$ of enzyme activities seen in normal chondrocytes. Co-transduction with SUMF1 produced up to a four-fold increase of enzyme activity. The level of elevation was subject to the transduced cell type. These findings show the potential application of AAV vectors for therapy of MPS IVA, potentially with co-transduction of SUMF1.

In vivo experiments using an MPS IVA mouse model showed that after 12 weeks of a single intravenous administration of an AAV vector carrying GALNS cDNA, plasma enzyme activity levels were $8.5 \%$ of those observed in wild-type mice, which were increased up to $20 \%$ when the AAV-GALNS vector was co-administrated with the AAVSUMF1 vector. In tissues, GALNS enzyme activity levels in mice infused with the AAV-GALNS vector only were below $10 \%$ of wild-type levels, while the co-administration with AAV-SUMF1 allowed a significant increase in enzyme

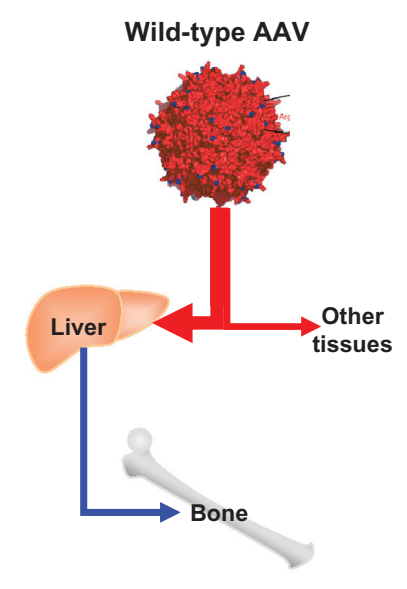

Delivered by cross-correction

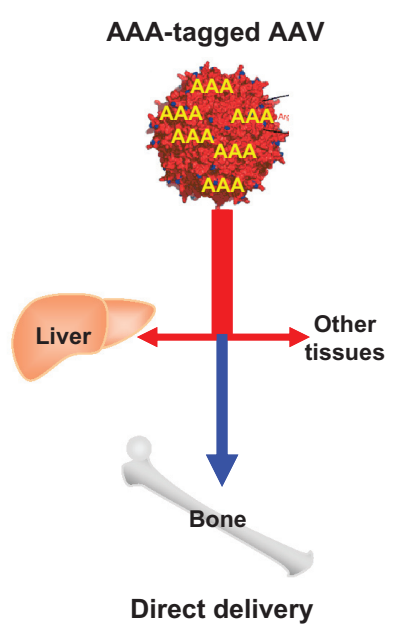

Figure 8 Mechanism of multiple AAA-targeting system.

Note: Viral capsid in the right panel has multiple copies of D8 integrated into capsid proteins, showing the retargeting of gene vector to bone (hydroxyapatite in the mineral region) schematically.

Abbreviations: AAA, triple adenine; AAV, adeno-associated virus; D8, eight Asp acidic amino acids.

activity in all the studied tissues, leading to GALNS activities about $30 \%$ of wild-type levels in liver, heart, and bone. Since theoretically only $10 \%$ of normal levels are required to move from a severe to an attenuated phenotype ${ }^{76}$ these results suggested the potential of AAV gene therapy for the treatment of MPS IVA.

Moreover, to target viral capsid to bone, a sequence encoding a stretch of eight Asp acidic amino acids (D8) was inserted immediately after the initial codon of the VP2 protein in the packing plasmid. The insertion of peptides did not affect the physical properties of the vector or infectious titers. ${ }^{77-79}$ The resultant modified vector produced a viral capsid containing multiple copies of the D8 peptide (Figure 8). After intravenous infusion in a mouse model, the modified vector was targeted to bone, released from hydroxyapatite, transduced in bone cells, and expressed its gene product in bone markedly higher than in mice treated with unmodified vector (unpublished data). This bone targeting gene therapy is designed to enhance the impact on the bone lesions of MPS IVA. This novel capsid will thus endow AAV vectors with the capacity to treat a variety of other LSDs with bone dysplasia, as well as other bone diseases and ultimately in the clinic.

\section{Conclusion}

MPS IVA is a prototype of severe progressive skeletal dysplasia which causes the disease in systemic bone and leads to death in the second or third decade of life unless the orthopedic surgical procedure and respiratory administration are adequately executed. Management of the patient should 
be concentrated in major medical centers where all medical specialties are accessible. Management should be a multidisciplinary approach to the patient, particularly for those who have serious spinal cord compression and respiratory problems. A comprehensive assessment of the individual patient at initial diagnosis is required, and should be followed by primary care clinicians. Supportive management, physiotherapy, and understanding of possible complications can significantly improve the quality of life of MPS IVA patients and their families. Families of the patients should be offered tailormade management including genetic counseling, supportive therapies, physiotherapies, and orthopedic interventions. Contact with other MPS IVA families, patients, and support groups, as well as the Morquio Foundation (http://www. morquio.com) or participation of the educational Morquio Symposium (http://www.morquioconference.org) should be helpful to access knowledge of the disease and exchange of experience in "Living with Morquio." It is required that physicians who take care of MPS IVA patients familiarize themselves with the most common complications, diagnosis of the disease, and locations of expert centers. Hopefully this will result in earlier diagnosis for patients, leading to better comprehensive therapy and avoidance of progression to irreversible damage. ERT, gene therapy, and HSCT are potential therapies that could be offered before or after onset of clinical sequelae of the enzyme deficiency. Although these treatments will not cure the disease, they provide the potential to rescue many patients from consequences of the disease, especially if treatment starts at an early stage. Developed systemic bone dysplasia remains a major challenge and novel innovative approaches such as bone targeting of enzyme should be considered. The International Morquio A Registry provides the largest source for analysis of data on the natural history of MPS IVA patients in terms of age of onset and diagnosis, initial and current signs and symptoms, disease progression, and disease severity and outcome. A natural history program, with clinical specialists available to assess each patient, will be required for further prognosis of the course of this disorder. Longitudinal observation of MPS IVA patients through an annual review will provide more precise and valuable information regarding the management of MPS IVA patients, including measuring effects of physical activity, supportive treatment, efficacy of therapy, and the clinical endpoints.

\section{Acknowledgments}

This work was supported by grants from the Austrian Research Society for Mucopolysaccharidoses and Related
Diseases, Austrian MPS Society, and International Morquio Organization (Carol Ann Foundation). WS was also supported by National Institutes of Health grant GM34182. TS, RM, and ST were supported by National Institutes of Health grant 8P20GM103464-08. ST and AM were supported by National Institutes of Health grant 1R01HD065767-01. The authors appreciate the International Morquio Organization (Carol Ann Foundation) for kindly providing the permission for the clinical pictures and figures. The content of the article has not been influenced by the sponsors. Editorial assistance to the manuscript was provided by Michelle Stofa at Nemours/ Alfred I duPont Hospital for Children.

\section{Disclosure}

The authors report no conflicts of interest in this work.

\section{References}

1. Meikle PJ, Hopwood JJ, Clague AE, Carey WF. Prevalence of lysosomal storage disorders. JAMA. 1999;281(3):249-254.

2. Applegarth DA, Toone JR, Lowry RB. Incidence of inborn errors of metabolism in British Columbia, 1969-1996. Pediatrics. 2000; 105(1):e10.

3. Nelson J. Incidence of the mucopolysaccharidoses in Northern Ireland Hum Genet. 1997;101(3):355-358.

4. Poorthuis BJ, Wevers RA, Kleijer WJ, et al. The frequency of lysosomal storage diseases in The Netherlands. Hum Genet. 1999;105(1-2): 151-156.

5. Pinto R, Caseiro C, Lemos M, et al. Prevalence of lysosomal storage diseases in Portugal. Eur J Hum Genet. 2004;12(2):87-92.

6. Morquio L. Sur une forme de dystrophie osseuse familiale. Archives de Médecine des Infants. 1929;32:129-135. French.

7. Tomatsu S, Montaño AM, Oikawa H, et al. Mucopolysaccharidosis type IVA (Morquio A disease): clinical review and current treatment. Curr Pharm Biotechnol. 2011;12(6):931-945.

8. Rodriguez M, Miller TL, Mackenzie WG, Ditro C, Chidekel AS, Shaffer TH. Characteristics of impulse oscillometry and thoracoabdominal motion in children with thoracic cage disorders. Pediatr Pulmonol. 2010;45(7):679-686.

9. Chatuparisute P, Shinohara Y, Kirchhoff C, Fischer F, Milz S. Immunohistochemical composition of the human lunotriquetral interosseous ligament. Appl Immunohistochem Mol Morphol. 2012; 20(3):318-324.

10. Liu CY, Kao WW. Lumican promotes corneal epithelial wound healing. Methods Mol Biol. 2012;836:285-290.

11. Imagama S, Sakamoto K, Tauchi R, et al. Keratan sulfate restricts neural plasticity after spinal cord injury. J Neurosci. 2011;31(47): 17091-17102.

12. Montaño AM, Tomatsu S, Gottesman GS, et al. International Morquio A Registry: clinical manifestation and natural course of Morquio A disease. J Inherit Metab Dis. 2007;30(2):165-174.

13. Montaño AM, Tomatsu S, Brusius A, et al. Growth charts for patients affected with Morquio A disease. Am J Med Genet A. 2008;146A(10): 1286-1295.

14. Glössl J, Kresse H. Impaired degradation of keratan sulfate by Morquio A fibroblasts. Biochem J. 1982;203(1):335-338.

15. Tomatsu S, Okamura K, Taketani T, et al. Development and testing of new screening method for keratan sulfate in mucopolysaccharidosis IVA. Pediatr Res. 2004;55(4):592-597.

16. Thonar EJ, Pachman LM, Lenz ME, Hayford J, Lynch P, Kuettner KE. Age related changes in the concentration of serum keratan sulphate in children. J Clin Chem Clin Biochem. 1988;26(2):57-63. 
17. Brighton CT, Sugioka Y, Hunt RM. Cytoplasmic structures of epiphyseal plate chondrocytes. Quantitative evaluation using electron micrographs of rat costochondral junctions with specific reference to the fate of hypertrophic cells. J Bone Joint Surg Am. 1973;55(4):771-784.

18. Brighton CT, Hunt RM. Histochemical localization of calcium in the fracture callus with potassium pyroantimonate: possible role of chondrocyte mitochondrial calcium in callus calcification. J Bone Joint Surg Am. 1986;68(5):703-715.

19. Mackie EJ, Ahmed YA, Tatarczuch L, Chen KS, Mirams M. Endochondral ossification: how cartilage is converted into bone in the developing skeleton. Int J Biochem Cell Biol. 2008;40(1):46-62.

20. Hintze JP, Tomatsu S, Fujii T, et al. Comparison of liquid chromatography-tandem mass spectrometry and sandwich ELISA for determination of keratan sulfate in plasma and urine. Biomark Insights. 2011;6:69-78

21. Tomatsu S, Dieter T, Schwartz IV, et al. Identification of a common mutation in mucopolysaccharidosis IVA: correlation among genotype, phenotype, and keratan sulfate. J Hum Genet. 2004;49(9): 490-494.

22. Tomatsu S, Montaño AM, Oguma T, et al. Validation of keratan sulfate level in mucopolysaccharidosis type IVA by liquid chromatography-tandem mass spectrometry. J Inherit Metab Dis. Epub January 27, 2010.

23. Tomatsu S, Montaño AM, Ohashi A, et al. Enzyme replacement therapy in a murine model of Morquio A syndrome. Hum Mol Genet. 2008;17(6):815-824.

24. Tomatsu S, Montaño AM, Dung VC, et al. Enhancement of drug delivery: enzyme-replacement therapy for murine Morquio A syndrome. Mol Ther. 2010;18(6):1094-1102.

25. Alméciga-Díaz CJ, Rueda-Paramo MA, Espejo AJ, et al. Effect of elongation factor 1alphapromoter and SUMF1 over in vitro expression of N-acetylgalactosamine-6-sulfate sulfatase. Mol Biol Rep. 2009;36(7): $1863-1870$

26. Brailsford JF. Chondro-osteo-dystrophy. Roentgenopgraphic and clinical features of a child with dislocation of vertebrae. Am J Sur. 1929;7:404-410.

27. Pedrini V, Lennzi L, Zambotti V. Isolation and identification of keratosulphate in urine of patients affected by Morquio-Ullrich disease. Proc Soc Exp Biol Med. 1962;110:847-849.

28. Orii T, Minami R, Chiba G, et al. Study on Morquio syndrome. Bone metabolism. 1971;(5):72-78. Japanese.

29. Orii T, Kiman T, Sukegawa K. Two brothers with the late-onset form of Nacetylgalactosamine-6-sulphate sulphatase deficiency. Connecrive Tissue. 1981;13:169-175.

30. Sukegawa K, Orii T. Residual activity in fibroblasts from two brothers with the late-onset form of $\mathrm{N}$-acetylgalactosamine-6-sulphate sulphatase deficiency. J Inherit Metab Dis. 1982;5(4)231-232.

31. Hecht JT, Scott CI Jr, Smith TK, Williams JC. Mild manifestations of the Morquio syndrome. Am J Med Genet. 1984;18(2):369-371.

32. Masue M, Sukegawa K, Orii T, Hashimoto T. N-acetylgalactosamine6-sulfate sulfatase in human placenta: purification and characteristics. J Biochem. 1991;110(6):965-970.

33. Tomatsu S, Fukuda S, Masue M, et al. Morquio disease: isolation, characterization and expression of full-length cDNA for human $\mathrm{N}$-acetylgalactosamine-6-sulfate sulfatase. Biochem Biophys Res Commun. 1991;181(2):677-683.

34. Nakashima Y, Tomatsu S, Hori T, et al. Mucopolysaccharidosis IV A: molecular cloning of the human $\mathrm{N}$-acetylgalactosamine-6-sulfatase gene (GALNS) and analysis of the 5 '-flanking region. Genomics. 1994;20(1):99-104.

35. Fukuda S, Tomatsu S, Masue M, et al. Mucopolysaccharidosis type IVA. N-acetylgalactosamine-6-sulfate sulfatase exonic point mutation in classical Morquio and mild cases. J Clin Invest. 1992;90(3): 1049-1053.

36. Tomatsu S, Fukuda S, Cooper A, et al. Mucopolysaccharidosis IVA: identification of a common missense mutation I113F in the N-Acetylgalactosamine-6-sulfate sulfatase gene. Am J Hum Genet. 1995;57(3):556-563.
37. Yamada N, Fukuda S, Tomatsu S, et al. Molecular heterogeneity in mucopolysaccharidosis IVA in Australia and Northern Ireland: nine novel mutations including T312S, a common allele that confers a mild phenotype. Hum Mutat. 1998;11(3):202-208.

38. Montaño AM, Yamagishi A, Tomatsu S, et al. The mouse $\mathrm{N}$-acetylgalactosamine-6-sulfate sulfatase (Galns) gene: cDNA isolation, genomic characterization, chromosomal assignment and analysis of the 5'-flanking region. Biochim Biophys Acta. 2000;1500(3):323-334.

39. Tomatsu S, Montaño AM, Nishioka T, et al. Mutation and polymorphism spectrum of the GALNS gene in mucopolysaccharidosis IVA (Morquio A). Hum Mutat. 2005;26(6):500-512.

40. Tomatsu S, Montaño AM, Lopez P, et al. Determinant factors of spectrum of missense variants in mucopolysaccharidosis IVA gene. Mol Genet Metab. 2006;89(1-2):139-149.

41. Tomatsu S, Montaño AM, Gutierrez M, et al. Characterization and pharmacokinetic study of recombinant human $\mathrm{N}$-acetylgalactosamine6-sulfate sulfatase. Mol Genet Metab. 2007;91(1):69-78.

42. Sukegawa K, Nakamura H, Kato Z, et al. Biochemical and structural analysis of missense mutations in $\mathrm{N}$-acetylgalactosamine-6-sulfate sulfatase causing mucopolysaccharidosis IVA phenotypes. Hum Mol Genet. 2000;9(9):1283-1290.

43. Tomatsu S, Orii KO, Vogler C, et al. Mouse model of $\mathrm{N}$-acetylgalactosamine-6-sulfate sulfatase deficiency (Galns-/-) produced by targeted disruption of the gene defective in Morquio A disease. Hum Mol Genet. 2003;12(24):3349-3358.

44. Tomatsu S, Gutierrez M, Nishioka T, et al. Development of MPS IVA mouse (Galnstm(hC79S.mC76S)slu) tolerant to human $\mathrm{N}$-acetylgalactosamine-6-sulfate sulfatase. Hum Mol Genet. 2005; 14(22):3321-3335.

45. Tomatsu S, Vogler C, Montaño AM, et al. Murine model (Galns(tm(C76S)slu)) of MPS IVA with missense mutation at the active site cysteine conserved among sulfatase proteins. Mol Genet Metab. 2007;91(3):251-258.

46. De Franceschi L, Roseti L, Desando G, Facchini A, Grigolo B. A molecular and histological characterization of cartilage from patients with Morquio syndrome. Osteoarthritis Cartilage. 2007;15(11):1311-1317.

47. Borowski A, Thacker MM, Mackenzie WG, Littleton AG, Grissom L. The use of computed tomography to assess acetabular morphology in Morquio-Brailsford syndrome. J Pediatr Orthop. 2007;27(8):893-897.

48. Dhawale AA, Thacker MM, Belthur MV, Rogers K, Bober MB, Mackenzie WG. The lower extremity in Morquio syndrome. J Pediatr Orthop. 2012;32(5):534-540.

49. Dullenkopf A, Holzmann D, Feurer R, Gerber A, Weiss M. Tracheal intubation in children with Morquio syndrome using the angulated video-intubation laryngoscope. Can J Anaesth. 2002;49(2):198-202.

50. Aziz MF, Healy D, Kheterpal S, Fu RF, Dillman D, Brambrink AM. Routine clinical practice effectiveness of the Glidescope in difficult airway management: an analysis of 2,004 Glidescope intubations, complications, and failures from two institutions. Anesthesiology. 2011;114(1):34-41.

51. Weiss M, Hartmann K, Fischer JE, Gerber AC. Use of angulated videointubation laryngoscope in children undergoing manual in-line neck stabilization. Br J Anaesth. 2001;87(3):453-458.

52. Armstrong J, John J, Karsli C. A comparison between the GlideScope Video Laryngoscope and direct laryngoscope in paediatric patients with difficult airways - a pilot study. Anaesthesia. 2010;65(4):353-357.

53. Diaz JH, Belani KG. Perioperative management of children with mucopolysaccharidoses. Anesth Analg. 1993;77(6):1261-1270.

54. Buhain WJ, Rammohan G, Berger HW. Pulmonary function in Morquio's disease: a study of two siblings. Chest. 1975;68(1):41-45.

55. Theroux MC, Nerker T, Ditro C, Mackenzie WG. Anesthetic care and perioperative complications of children with Morquio syndrome. Pediatr Anesth. 2012;22(9):901-907.

56. Vellodi A, Young E, Cooper A, Lidchi V, Winchester B, Wraith JE. Long-term follow-up following bone marrow transplantation for Hunter disease. J Inherit Metab Dis. 1999;22(5):638-648. 
57. Tolar J, Grewal SS, Bjoraker KJ, et al. Combination of enzyme replacement and hematopoietic stem cell transplantation as therapy for Hurler syndrome. Bone Marrow Transplant. 2008;41(6):531-535.

58. Khanna G, Van Heest AE, Agel J, et al. Analysis of factors affecting development of carpal tunnel syndrome in patients with Hurler syndrome after hematopoietic cell transplantation. Bone Marrow Transplant. 2007;39(6):331-334.

59. Tomatsu S, Montaño AM, Gutierrez M, et al. Characterization and pharmacokinetic study of recombinant human N-acetylgalactosamine6-sulfate sulfatase. Mol Genet Metab. 2007;91(1):69-78.

60. Lim-Melia ER, Kronn DF. Current enzyme replacement therapy for the treatment of lysosomal storage diseases. Pediatr Ann. 2009;38(8): 448-455.

61. Kakkis ED, Muenzer J, Tiller GE, et al. Enzyme-replacement therapy in mucopolysaccharidosis I. N Engl J Med. 2001;344(3):182-188.

62. Simonaro CM, D'Angelo M,HeX, etal.Mechanism of glycosaminoglycanmediated bone and joint disease. Am J Pathol. 2008;172:112-122.

63. Sekido T, Sakura N, Higashi Y, et al. Novel drug delivery system to bone using acidic oligopeptide: pharmacokinetic characteristics and pharmacological potential. J Drug Target. 2001;9(2):111-121.

64. Yokogawa K, Miya K, Sekido T, et al. Selective delivery of estradiol to bone by aspartic acid oligopeptide and its effects on ovariectomized mice. Endocrinology. 2001;142(3):1228-1233.

65. Nishioka T, Tomatsu S, Gutierrez MA, et al. Enhancement of drug delivery to bone: characterization of human tissue-nonspecific alkaline phosphatase tagged with an acidic oligopeptide. Mol Genet Metab. 2006;88(3):244-255.

66. Millán JL, Narisawa S, Lemire I, et al. Enzyme replacement therapy for murine hypophosphatasia. J Bone Miner Res. 2008;23(6):777-787.

67. Gutiérrez MA, García-Vallejo F, Tomatsu S, et al. Construction of an adenoassociated, viral derived, expression vector to correct the genetic defect in Morquio A disease. Biomedica. 2008;28(3):448-459. Spanish.

68. Toietta G, Severini G, Traversari C, et al. Various cells retrovirally transduced with N-acetylgalactosoamine-6-sulfate sulfatase correct Morquio skin fibroblasts in vitro. Hum Gene Ther. 2001;12(16):2007-2016.

69. Hacein-Bey-Abina S, Garrigue A, Wang GP, et al. Insertional oncogenesis in 4 patients after retrovirus-mediated gene therapy of SCID-X1. $J$ Clin Invest. 2008;118(9):3132-3142.

70. Alexander IE, Cunningham SC, Logan GJ, Christodoulou J. Potential of AAV vectors in the treatment of metabolic disease. Gene Ther. 2008;15(11):831-839.

71. Carter BJ. Adeno-associated virus vectors in clinical trials. Hum Gene Ther. 2005;16(5):541-550.

72. Wu Z, Asokan A, Samulski R. Adeno-associated virus serotypes: vector toolkit for human gene therapy. Mol Ther. 2006;14(3):316-327.

73. Papadakis ED, Nicklin SA, Baker AH, White SJ. Promoters and control elements: designing expression cassettes for gene therapy. Curr Gene Ther. 2004;4(1):89-113.
74. Fraldi A, Biffi A, Lombardi A, et al. SUMF1 enhances sulfatase activities in vivo in five sulfatase deficiencies. Biochem J. 2007; 403(2): 305-312.

75. Fraldi A, Hemsley K, Crawley A, et al. Functional correction of CNS lesions in an MPS-IIIA mouse model by intracerebral AAVmediated delivery of sulfamidase and SUMF1 genes. Hum Mol Genet. 2007;16(22):2693-2702.

76. Cheng SH, Smith AE. Gene therapy progress and prospects: gene therapy of lysosomal storage disorders. Gene Ther. 2003;10(16):1275-1281.

77. Loiler SA, Conlon TJ, Song S, et al. Targeting recombinant adenoassociated virus vectors to enhance gene transfer to pancreatic islets and liver. Gene Ther. 2003;10(18):1551-1558.

78. Wu BW, Lu J, Gallaher TK, Anderson WF, Cannon PM. Identification of regions in the Moloney murine leukemia virus SU protein that tolerate the insertion of an integrin-binding peptide. Virology. 2000; 269(1):7-17.

79. Perabo L, Goldnau D, White K, et al. Heparan sulfate proteoglycan binding properties of adeno-associated virus retargeting mutants and consequences for their in vivo tropism. J Virol. 2006;80(14):7265-7269.

80. Matalon R, Arbogast B, Dorfman A. The enzymic defects in morquio and maroteaux-lamy syndrome. Biochem Biophys Res Commun. 1974;61:1450-1457.

81. Glössl J, Kresse H. A sensitive procedure for the diagnosis of $\mathrm{N}$-acetyl-galactosamine-6-sulfate sulfatase deficiency in classical Morquio's disease. Clin Chim Acta. 1978;88(1):111-119.

82. Di Ferrante N, Ginsberg LC, Donnelly PV, Di Ferrante DT, Caskey CT Deficiencies of glucosamine-6-sulfate or galactosamine-6-sulfate sulfatases are responsible for different mucopolysaccharidoses. Science. 1978;199(4324)79-81.

83. Bielicki J, Hopwood JJ. Human liver N-acetylgalactosamine 6-sulphatase. Purification and characterization. Biochem J. 1991; 279(Pt 2):515-520.

84. Tomatsu S, Fukuda S, Masue M, Sukegawa K, Masuno M, Orii T. Mucopolysaccharidosis type IVA: characterization and chromosomal localization of N-acetylgalactosamine-6-sulfate sulfatase gene and genetic heterogeneity. Am J Hum Genet. 1992;51(Suppl 4):A178, 699.

85. Oguma T, Tomatsu S, Okazaki O. Analytical method for determination of disaccharides derived from keratan sulfates in human serum and plasma by high-performance liquid chromatography/turbo-ionspray ionization tandem mass spectrometry. Biomed Chromatogr. 2007;21(4):356-362.

86. Alméciga-Díaz CJ, Montaño AM, Tomatsu S, Barrera LA. Adenoassociated virus gene transfer in Morquio A disease: effect of promoters and sulfatase-modifying factor 1. FEBS J. 2010;277(17): 3608-3619.

87. Slide 74. Educational CD for Morquio. Tucson, AZ: The Carol Ann Foundation and The International Morquio Organization; 2005.

88. Slide 53. Educational CD for Morquio. Tucson, AZ: The Carol Ann Foundation and The International Morquio Organization; 2005.

Research and Reports in Endocrine Disorders

\section{Publish your work in this journal}

Research and Reports in Endocrine Disorders is an international, peerreviewed, open access journal publishing original research, reports, reviews and commentaries on all areas of endocrinology, endocrine disorders and therapeutic interventions. The manuscript management system is completely online and includes a very quick and fair 